\title{
THE BRAZILIAN HIGHER EDUCATION: THE UNDERGRADUATE COURSES IN LIGHT OF ITS RECENT POLICIES
}

\author{
Silvia Regina Machado de Campos, \& Roberto Henriques \\ Nova Information Management School (NOVA IMS), Universidade Nova de Lisboa (Portugal)
}

\begin{abstract}
Higher Education has been considered of unprecedented relevance when it comes to the effects of globalization on countries as they are responsible for people's training and knowledge generation. HEIs cannot avoid the inevitable global environment, as they are more exposed to the inequalities among the best-internationalized institutions as part of the world system of Higher Education. Despite, they continue to be confronted with some challenges as access, equity, quality and relevance. The Higher Education System in Brazil is the most extensive higher education system and the one who has relied the most on the private for-profit sector among the Latin America countries, and its university governance has assumed characteristics that you do not necessarily see elsewhere. Thus, this research addresses a significant gap: the limited studies considering the context of the HEIs in developing countries. Based on this context, this paper proposes to present an overview of the Brazilian Higher Education to discuss its characteristics, based on the literature review, and to analyze the data of the undergraduate courses, from 2010 to 2015, organized according to the OECD main areas and based on the Higher Education Census microdata. It intends to contribute to a more strategic view concerning the offer conditions of the HEIs, identifying its most recent trends and challenges. We adopted an exploratory and descriptive research methodology and followed an inductive approach to a quantitative research strategy. We used an artificial type of Neural Network (ANN), the Self-Organizing Map (SOM) technique, as a method of data analysis, as it mapped data in an easily interpreted form, capable of organizing large, complex datasets robustly and reliably. The main conclusions of the paper were that students have access to the tertiary level of study, mainly in science and engineering fields, areas of preference among abroad students. In Brazil, the findings pointed out the opposite, as the Brazilian Higher Education was concentrated mainly in Education and Social Sciences, Business and Law areas.
\end{abstract}

Keywords: Knowledge discovery, higher education, higher education institutions, self-organizing map.

\section{An introduction to the higher education in Brazil}

The entrance to Higher Education Institutions (HEIs) in Brazil is based on the completion of the secondary school and on the achievement of some specific exams conducted by the HEIs themselves called "vestibular." Despite that, in 1998, the Ministry of Education implemented another exam called National Examination of Secondary Education (Exame Nacional do Ensino Médio, ENEM, in Portuguese) which, since 2009, was the official entrance exam. Since then, lots of HEIs have replaced their proper entry exams by ENEM or used it in addition to theirs. ENEM is not mandatory but has been considered a prerequisite for students who want to enroll themselves or participate in various government scholarship and funding programs during their undergraduate courses.

The HEIs are under specific administrative categorization in Brazil. The public ones are maintained by the government in the form of (1) Federal, (2) State or (3) Municipal institutions. They are financed by the State and do not charge tuition or monthly fees. Private HEIs are managed by individuals or legal entities under private law, whether or not-for-profit.

Regarding the academic classification, HEIs may receive different denominations. (1) The University is a multidisciplinary and comprehensive academic institution that has institutionalized intellectual production, besides presenting minimum academic qualification requirements (one-third of masters and doctorates). It is autonomous to create courses and academic and administrative offices, to issue diplomas, to establish curricula and number of vacancies, respecting the current legislation and the constitutional norm. The universities are the only ones obliged to do research. (2) The University Center is a multicurricular institution, which covers one or more areas of knowledge. It is like the University regarding structure but does not present the requirement for institutionalized research. (3) The College or Faculty has two connotations. The first is that of an HEIs that does not have the autonomy to confer titles and diplomas. Also, it does not have the function of promoting graduate studies. The second connotation 
refers to specific organic or institutes or similar organizations. The colleges or faculties are concentrated on teaching. Some of them can also develop community services. (4) The Federal Institutes are units focused on technical training, with professional qualification in diverse areas and the (5) Federal Center of Technological Education equates to university center.

The Brazilian HE offers (1) the undergraduate courses, which are tertiary degree courses, open to candidates who have completed the secondary school or equivalent and have been classified in an entrance process, conferring the Bachelor, Licentiate (teacher training) or Technology degrees; (2) the stricto sensu graduate courses which comprises master's and doctoral programs, which confer diploma to the graduates; (3) the specialization or lato sensu graduate courses, which are programs open to undergraduate candidates who meet the requirements of the educational institutions, and confer them certificates; (4) the medical residency, which is a lato sensu graduate program, specializing in the medical field; (5) the multiprofessional residency in health, which is also a lato sensu graduate program in health areas other than medicine; and (6) the extension or service community courses which are a training program, aimed at strengthening the relationship between university and society.

The undergraduate courses can be offered in two distinct modes, the classroom mode and the e-learning mode. In Brazil, the e-learning mode courses are also less expensive than the classroom ones, can achieve a higher number of students in different geographic areas - as the Brazilian territory is vast - and have increased its offer substantially in the last decade.

Brazilian Higher Education has some specific characteristics. The entrance to the public HEIs, at the undergraduate level, is very competitive as the public institutions are considered the best and are tuition-free. Historically, only the students with a higher economic and social status can achieve the scores to study in the best public universities. On the other hand, public primary and secondary schools in the country are mainly frequented by lower-income students. According to Fischman (2005), Brazil is still recognized as a 'racial democracy,' although the inequality is at one of the highest levels in the world and, as a consequence, impacts all levels of Education.

\section{Objectives}

Considering the above overview of the Brazilian Higher Education, this paper proposes to analyze the data of the undergraduate courses, from 2010 to 2015, organized according to the OECD main areas.

\section{Methods}

This research is focused on the Higher Education undergraduate courses offered from 2010 to 2015 (Table 1), organized according to the OECD Main Areas (Table 2).

Table 1. Higher Education Institutions and their undergraduate courses, 2010-2015.

\begin{tabular}{|l|c|c|c|c|c|c|}
\hline & $\mathbf{2 0 1 0}$ & $\mathbf{2 0 1 1}$ & $\mathbf{2 0 1 2}$ & $\mathbf{2 0 1 3}$ & $\mathbf{2 0 1 4}$ & $\mathbf{2 0 1 5}$ \\
\hline HEIs & 2,378 & 2,365 & 2,416 & 2,391 & 2,368 & 2,364 \\
\hline Courses & 28,577 & 30,420 & 31,866 & 32,049 & 32,878 & 33,501 \\
\hline
\end{tabular}

Source: Mec, Inep, 2010-2015.

It adopts an exploratory and descriptive research methodology and follows an inductive approach to a quantitative research strategy. It uses an artificial type of Neural Network (ANN), the Self-Organizing Map (SOM) technique, as a method of data analysis, as it maps data in an easily interpreted form, capable of organizing large, complex datasets robustly and reliably. SOM is a non-supervised neural network which also explores patterns hidden in the data. It is complemented by some descriptive statistics analysis to summarize the data time series. This research used the GeoSOM Suite tool.

Table 2. Variables for undergraduate courses proportion according to OECD Main Area, per year.

\begin{tabular}{l|l|l}
\hline \multicolumn{2}{|l|}{ Variable } & \multicolumn{1}{c}{ Description } \\
\hline$x_{1}$ & nC_O1_year & OECD main area 1, Education \\
\hline$x_{2}$ & nC_O2_year & OECD main area 2, Humanities and Arts \\
\hline$x_{3}$ & nC_O3_year & OECD main area 3, Social Sciences, Business and Law \\
\hline$x_{4}$ & nC_O4_year & OECD main area 4, Science, Math and Computing \\
\hline$x_{5}$ & nC_O5_year & OECD main area 5, Engineering, Production, and Construction \\
\hline$x_{6}$ & nC_O6_year & OECD main area 6, Agriculture and Veterinary \\
\hline$x_{7}$ & nC_O7_year & OECD main area 7, Health and Social Welfare \\
\hline$x_{8}$ & nC_O8_year & OECD main area 8, Services \\
\hline
\end{tabular}


In this study, SOM is used to assess the potential relationship among Higher Education (HE) components - Higher Education Institutions and their undergraduate courses and, further, to identify the institutions that focus their offer in a specific area of knowledge (niche). The specific advantages of SOM algorithm and its classification and visualization ability for large Higher Education data are to detect, not only the hidden factors responsible for the data structure observation but to find some HE specific features that will be presented in the discussion.

\section{Discussion on a global vision of the undergraduate courses' areas}

In 2015, the total number of HEIs had dropped in Brazil. On the contrary, the number of undergraduate courses has increased over the period. Despite this increase, according to the data analyzed, this supply has migrated among different areas of knowledge, which may indicate some tendencies regarding potential demand.

Taken the year of 2010 as a point of depart and a reference for the global analysis, Table 3 indicates the distribution of the number of courses offered by the HEIs, in each area of predominance, per year, during the period studied. It was observed that, along the period, the offer condition varied significantly. In general, from 2010 to 2015, there was a reduction in the offer conditions for all areas, except for Engineering, Production, and Construction areas. Also, there was a highlight for the Science, Mathematics, and Computing Area, which configured itself as an independent cluster in 2011. Also, there were an increase in the proportion of the courses among the diversified cluster for the Agriculture and Veterinary; and Services areas (Table 3).

In 2010 and 2013, the Education area concentrated most of the offered courses. Along the period, Education is also one of the most prominent areas concerning the offer conditions in the country.

In the year of 2014, a group of institutions emerges, in a different cluster, offering courses in several areas, herein titled as comprehensive. The year of 2014 represented one of the most extreme scenarios considering the distribution of courses, as there was a significant drop in all areas with some of the worst numbers in the last five years.

Therefore, the year of 2015 demonstrates an attempt to recover from this scenario, with an increase in the diversified group, which raises the supposition that the small institutions are getting smaller.

Comparing to other OECD countries, over the past two decades, in some countries, more students have access to the tertiary level of study, mainly in science and engineering fields which is the opposite to what was achieved. Worldwide, some fields are more popular among students. The areas of science and engineering, per example, have a preference. Despite this trend, Brazilian Higher Education is concentrated mainly in Education and Social Sciences, Business and Law areas. Only in 2015, it was observed an increase in the offer of Engineering, Production and Constructions courses from 19.64\% to $29.35 \%$ and also in the areas of Agriculture and Veterinary, Health and Social Welfare, and Services which were grouped by the diversified cluster (Table 3).

\section{Conclusions}

HEIs play a significant role in the knowledge economy. For centuries the new scientific knowledge has been produced, validated and disseminated mainly by the Universities. The efficiency of the higher education system and higher education is a complicated socio-economic relationship which generates various effects throughout the society and country development. Based on the data analyzed some new information can be depicted, contributing to a more prospective and strategic view of the Brazilian Higher Education and generating some useful insights concerning trends and future challenges for Higher Education offer conditions also in similar countries or HE systems.

Along the period, the total number of HEIs varied slightly, but the number of undergraduate courses increased. The HEIs which were specialized in a knowledge area called a niche institution, on the contrary, suffered a decrease during the same period, in all areas, going in the opposite direction of the world trend. Despite this fact, the literature points out that the niche market, which constitutes a tendency, would allow HEIs to compete in a more demanding, fast-changing and threatening environment. Some other trends were observed concerning the data analyzed: the areas of Education and Social Sciences, Business and Law, predominate in Brazil along the period. On the contrary, the areas of Science, Mathematics, and Computing; Humanities and Arts; and Engineering, Production and Construction are the ones with the lowest number of specialized (niche) institutions which is opposite to other OECD countries. The Agriculture and Veterinary and Services are smaller and not representative of the data group. Most of the HEIs that compose the niches were also private institutions characterized mainly as faculties, smaller institutions dedicated to teaching. It was also observed the niches had joined themselves in ever smaller groups oh HEIs along the time. On the other hand, a group of faculties delivering a variety 
of courses in different areas (so-called comprehensive) appeared. These two groups with different segmentation strategies coexist. The first group illustrates the niche specialization, while the second one, an opposite trend, illustrates the diversification.

The current Brazilian political and economic situation propitiate opportunities to offer courses jointly, as the institutions dispose of different funding and administrative arrangements, and the planning and establishment of new courses can be time-consuming.

As the Higher Education in Brazil is mainly provided by the private sector, this will require new mechanisms of management to grant its sustainability to the long term. It is more evident that the HEIs will compete for students and financial resources, quality, and variety of services offered, diversifying, and adapting themselves according to competitive forces to new constraints and opportunities. Thus, the challenge will be to restate the HEIs mission to be more focused on quality and to pursue student's outcomes.

Table 3. Evolution of undergraduate courses per area during 2010-2015.

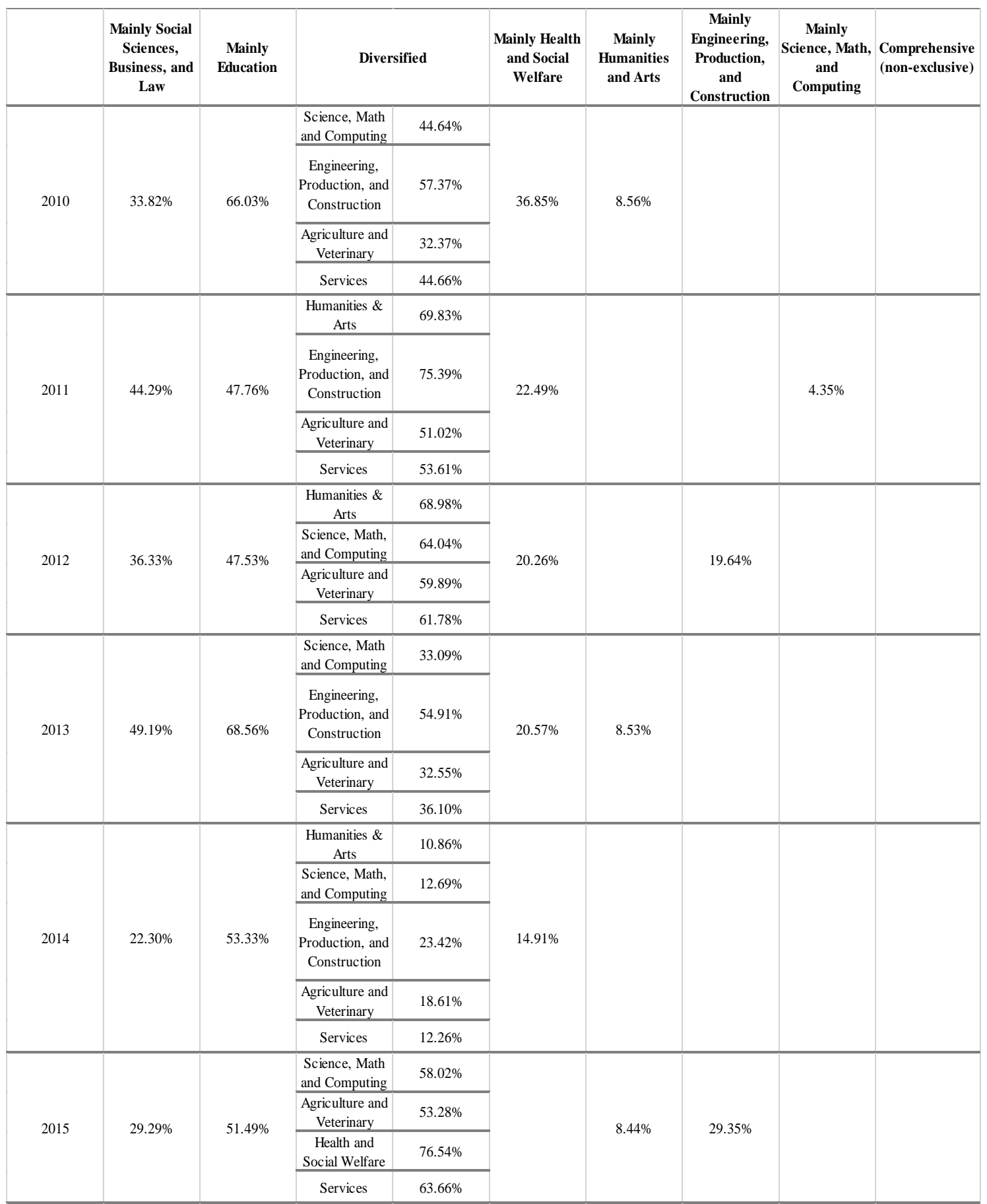




\section{References}

Altbach, Philip G. "Globalisation and the University: Myths and Realities in an Unequal World." Tertiary Education and Management 10 (2004): 3-25.

Blackboard. Future Forward: The Next Twenty Years of Higher Education. (2017).

Brasil. "Ldb, Law No. 9.394, Lei De Diretrizes E Bases da Educação." edited by Presidência da República. Brasília: Casa Civil, Subchefia para Assuntos Jurídicos, 1996. http://www.planalto.gov.br/ccivil_03/LEIS/L9394compilado.htm.

Bryman, Alan. Social Research Methods. 4th ed.: Oxford University Press, 2012.

Campos, Sílvia Regina Machado de, Roberto Henriques, and Mitsuru Higuchi Yanaze. "Higher Education in Brazil: An Exploratory Study Based on Supply and Demand Conditions." journal article. Universal Access in the Information Society (2017): 1-23. https://doi.org/10.1007/s10209-0170537-9. http://dx.doi.org/10.1007/s10209-017-0537-9.

Chang, Chen-Chi. "The of Value Knowledge Created by Individual Scientists and Research Groups." Journal of Scholarly Publishing 39, no. 3 (2008): 274-93. https://doi.org/https://doi.org/10.1353/scp.0.0006.

Emilia, Gogu, Mureşan Mihaela, and Turdean Marinella. "Statistical Comparative Analyses of the Public and Private Tertiary Education in Romania, 2000 - 2012." Procedia Economics and Finance 10 (2014): 23-31.

Fischmann, Roseli. "Historical and Legal Remarks on Cultural Diversity and Higher Education in Brazil in the Context of the School System." Higher Education Policy 18 (2005): 375-95.

Gacel-Avila, Jocelyne. "Comprehensive Internationalisation in Latin America." Higher Education Policy 25 (2012): 493-510.

Havas, Attila. "Universities and the Emerging New Players: Building Futures for Higher Education." Technology Analysis \& Strategic Management 21, no. 3 (2009 2009): 425-43 Pii 910144309. https://doi.org/10.1080/09537320902750905. <Go to ISI>://WOS:000264794300010.

Henriques, Roberto André Pereira. "Artificial Intelligence in Geospatial Analysis: Applications of SelfOrganizing Maps in the Context of Geographic Information Science." PhD, Universidade Nova de Lisboa - ISEGI, 2010.

Henriques, Roberto, Fernando Bacao, and Victor Lobo. "Exploratory Geospatial Data Analysis Using the Geosom Suite." Computers, Environment and Urban Systems 36 (2012): 218-32.

Holsworth, Eugene Trani; Robert. "The Indispensable University: Higher Education, Economic Development and the Knowledge Economy." edited by Inc. Rowman and littlefield Publishers, 115-18. International Journal of Educational Advancement, 2010.

Leisyte, Liudvika, and Hugo Horta. "Introduction to a Special Issue: Academic Knowledge Production, Diffusion and Commercialization: Policies, Practices and Perspectives ". Science and Public Policy 38, no. 6 (2011): 422-24. https://doi.org/10.3152/030234211X12960315267697.

McCowan, Tristan. "Universities and the Post-2015 Development Agenda: An Analytical Framework." journal article. Higher Education 72, no. 4 (2016): 505-23. https://doi.org/10.1007/s10734-0160035-7. http://dx.doi.org/10.1007/s10734-016-0035-7.

Mendivil, Jorge Luis Ibarra. "The New Providers of Higher Education." Higher Education Policy 15 (2002): 353-64.

OECD. "Education at a Glance 2016: Oecd Indicators." no. 19 (2016): 502.

Salto, Dante J. "To Profit or Not to Profit: The Private Higher Education Sector in Brazil." High Educ (2017). https://doi.org/10.1007/s10734-017-0171-8. Published online.

Schwartzman, Simon, Rómulo Pinheiro, and Pundy Pillay (eds.). Higher Education in the Brics Countries: Investigating the Pact between Higher Education and Society. Higher Education Dynamics. Edited by Peter Maassen and Johan Müller. Vol. VOLUME 44, New York London: Springer Dordrecht Heidelberg 2015. doi:10.1007/978-94-017-9570-8.

Stanek, Christina. "The Educational System of Brazil." IEM Spotlight 10, no. 1 (2013).

Tan, Christine Nya-Ling. "Enhancing Knowledge Sharing and Research Collaboration among Academics: The Role of Knowledge Management." High Educ 71 (2016): 525-56. https://doi.org/10.1007/s10734-015-9922-6. 